\title{
VALIDATION OF K-SENSE AGAINST INDIRECT CALORIMETRY AND ACCELEROMETRY
}

original paper

( ) University School of Physical Education in Wroclaw

DOI: https://doi.org/10.5114/hm.2019.79042

\author{
SAMI YLI-PIIPARI ${ }^{1}$, KAZI I. ZAMAN ${ }^{2}$, JOSEPH C. FISH ${ }^{3}$, TIMOTHY W. HNAT ${ }^{2}$ \\ ${ }^{1}$ University of Georgia, Athens, United States \\ ${ }^{2}$ University of Memphis, Memphis, United States \\ ${ }^{3}$ Health Science Center, University of Tennessee, Knoxville, United States
}

ABSTRACT

Purpose. Considering the difficulty of accurately estimating energy expenditure (EE) in habitual physical activity (PA), efforts to improve estimation accuracy are well warranted. The aim of the study was, first, to validate the K-Sense EE estimation system to improve EE estimation accuracy of human low-intensity activities, and, second, to compare K-Sense EE estimation values against ActiGraph (GT3X+) accelerometer-derived EE estimates.

Methods. A comparative analysis investigated the K-Sense EE estimation values against indirect calorimetry and ActiGraph $(G T 3 X+)$ EE estimates. A sample of 18 participants (age: $24.0 \pm 5.2$ years) performed eight sedentary/low intensity lifestyle activities, each wearing K-Sense with sensors attached to right wrist and ankle.

Results. The K-Sense estimation accuracy ranged from 89.4\% to 99.9\%, outperforming ActiGraph equations, which were found to overestimate EE of these low-intensity activities, achieving 70.3\% estimation accuracy at best. T-tests showed no statistically significant differences between K-Sense and indirect calorimetry values. Bland-Altman plots, however, illustrated an EE estimation error ranging from -9 to $7 \mathrm{kcal}$ (with 95\% confidence limits of agreement) among individuals.

Conclusions. EE evaluation with low-cost inertial measurement units, such as those found in K-Sense, is a valid method in comparison with indirect calorimetry and ActiGraph accelerometry.

Key words: energy expenditure, physical activity, behavioural research

\section{Introduction}

Obesity, an unwanted positive energy balance, is a serious epidemic that can be largely contributed to by excessive food intake and diminished physical activity (PA). In fact, more than $1 / 3$ of United States (U.S.) adults (35.7\%) are obese [1]. Typical obesity-related conditions include heart disease, stroke, type 2 diabetes, and certain types of cancer, which are some of the leading causes of preventable death. The estimated annual medical cost of obesity in the U.S. is $\$ 147$ billion per year, with annual medical spending $42 \%$ higher for an obese individual compared with a lean individual [2]. Although the benefits of healthy weight are well documented, maintaining healthy energy balance has shown to be difficult.
Accurate assessment of energy expenditure (EE) is a critical component of successful weight management. Total EE can be expressed in three components: basal metabolic rate (covers the energetic cost of the processes essential for life), diet-induced thermogenesis (results from the digestion, absorption, and conversion of food into energy), and activity-induced EE [3]. Activity-induced EE is associated with muscular contractions involved in body movements and maintenance of posture, and it is the most variable component of total EE [3]. Research has shown that individuals, regardless of their weight status or sex, tend to under-report energy intake [4] and overestimate their EE [5, 6] and PA [5, 7, 8]. For instance, Willbond et al. [6], examining normal weight participants, showed that for a $200-\mathrm{kcal}$ exercise bout, the participant estimation ranged from

Correspondence address: Sami Yli-Piipari, University of Georgia, 349 Ramsey Building, 330 River Road, 30602 Athens, United States, e-mail: syp@uga.edu

Received: September 20, 2017

Accepted for publication: October 2, 2018

Citation: Yli-Piipari S, Zaman KI, Fish JC, Hnat TW. Validation of K-Sense against indirect calorimetry and accelerometry. Hum Mov. 2019;20(1):38-47; doi: https://doi.org/10.5114/hm.2019.79042. 
120 to $4000 \mathrm{kcal}$. In addition, studies have reported that PA and EE estimation is less accurate in overweight persons $[5,9]$ and that overestimation is greater with older age and higher body fatness [10].

Owing to the complex nature of EE, studies to design new technology for more accurate assessment of PA and EE have been recommended [8, 11]. Technologies such as metabolic carts and calorimeter rooms provide the most accurate assessment of total EE; however, they are difficult and intrusive to wear or place a significant burden on a person. Similarly, doubly labelled water is regarded as an accurate approach to EE evaluation, but it is relatively expensive and the consumption of doses of doubly labelled water, consisting on two ${ }^{2} \mathrm{H}_{2}{ }^{18} \mathrm{O}$ isotypes, can be burdening to research participants [12]. Currently, most epidemiological studies have relied on waist- or wrist-mounted accelerometers [13], which are devices that measure body movements based on changes in motion. Most accelerometers in use are micro-electromechanicalsystem capacitive accelerometers, capable of detecting both static and dynamic accelerations in either two or three orthogonal planes (anteroposterior, mediolateral, and vertical) [14]. Depending on a target population and aims of a study, accelerometer data are normally collected with the use of one or several body-mounted devices attached around body parts, such as waist/ hip, wrist, upper thigh, or ankle [13].

Accelerometers are typically designed to categorize the duration and intensity of habitual PA of humans [15]. Accelerometers use validated algorithms to convert raw accelerometer-derived counts to EE estimates, or apply specific machine-learning techniques to extract raw acceleration data translated into EE estimation models [16]. Current linear-regression-based EE equations have normally been developed by predicting 'ground truth' values, such as indirect calorimetry, doubly labelled water, or direct observation values, from the values of accelerometer signals and other physical characteristics, such as age, sex, height, weight, and body mass [17]. Numerous different regressions equations for various types of human activities have been created. For example, the ActiGraph GT3X+ (ActiLife 6) accelerometer EE equations have used: (a) a single linear regression to predict equations based on either walking and running [18-24] or moderateintensity lifestyle activities [8, 20]; or (b) a 2-regression model to distinguish between continuous walking/running and intermittent lifestyle activity on the basis of the variability in the accelerometer counts [24]. In general, regression equations developed for walking and jogging slightly overestimate the energy cost of walking and light-intensity activities, while they greatly underestimate the energy cost of moderate-intensity lifestyle activities. In contrast, regression equations developed with the use of moderate intensity lifestyle activities provide a closer estimate of EE, but greatly overestimate the energy cost of sedentary and light activities and underestimate the energy cost of vigorous activities [23, 25]. More recently, methodologies such as Gaussian process-based regression [26], hidden Markov method [27], or machine learning [28] have been introduced to improve the accuracy of the accelerometer-based EE estimation. Although these novel approaches have shown some potential to improve the accuracy of EE estimation, early evidence suggests that their generalizability is limited because of a large inter-subject variance and small sample sizes [27]. In addition, the hidden Markov method requires acceleration data to be collected in different epoch lengths, not available in Crouter 2-regression [24], Hendelman [20], Freedson VM3 [29], or Swartz [30] estimation models [25]. The raw-data-based analytic models, particularly multidimensional algorithms, are still being developed, validated, and optimized by researchers and device manufacturers [16]. To improve the accuracy of accelerometer-based EE estimation and overcome humans' tendency to overestimate their EE, it is important to design technology that facilitates successful weight management. This is especially significant when detecting total EE of overweight populations owing to light-intensity activities that account for the majority of the day [19, 23, 31]. To overcome this barrier and improve EE estimation accuracy of human light-intensity PA, an accelerometer-based K-Sense system was recently introduced [32, 33]. The K-Sense EE system uses movement data derived with inertial measurement units (IMUs), mounted to an individual's wrist and ankle [32].

The purpose of this study, building on the previous research on K-Sense, was twofold. Firstly, the study aimed to validate the K-Sense EE estimation system to improve EE estimation accuracy of human activities, and validate the K-Sense EE estimation against indirect calorimetry. On the basis of the findings of Zaman et al. [32, 33], it was hypothesized that the K-Sense equations would achieve 95\% EE estimation accuracy compared with indirect calorimetry in laboratory conditions. Secondly, the study aimed to compare K-Sense EE estimation values against ActiGraph (GT3X+) accelerometer-derived EE estimates. It was hypothesized that K-Sense would provide improved accuracy estimates on EE compared with current accelerometerderived equations of Crouter 2-regression [24], Hendelman [20], Freedson VM3 [29], and Swartz [30]. 


\section{Material and methods}

\section{Participants}

The sample comprised 18 (9 females and 9 males) individuals (age: $24.0 \pm 5.2$; BMI: $27.1 \pm 5.3 \mathrm{~kg} / \mathrm{m}^{2}$ ) from the Mid-South U.S. (Table 1), with 13 (> 70\%) being obese. All eligible subjects (inclusion criterion: $\mathrm{BMI}>$ $21 \mathrm{~kg} / \mathrm{m}^{2}$ ) who were willing to participate in the study were accepted. No participant incentives were available. In addition, before the participation, all subjects were screened for pregnancy or pathologies such as breathing difficulties that might have caused exclusion. All participants were asymptomatic, with no medical condition that might prevent their participation in the study.

\section{Experiment}

After signing the consent, the participants completed a background survey and the Physical Activity Readiness Questionnaire [34]. Next, their weight was measured without shoes or heavy outer garments to the nearest $0.1 \mathrm{~kg}$, with the use of electronic scales (Oregon Scientific ${ }^{\otimes}$, U.S.). Height was determined without shoes to the nearest $0.1 \mathrm{~cm}$, with a standard physician's scale, before fitting the participants with the testing equipment.

The experimental design applied in the study has already been reported elsewhere [32]. The experimental setup consisted of two supervised 50-minute laboratory session in which participants were asked to perform eight light-intensity activities [35]. The first session comprised lying and watching television, sitting quietly and watching television, standing quietly, and cleaning (sweeping a floor area of $4 \times 4$ feet). The second session involved sitting (working on a laptop), reclining and reading a book, putting away groceries (lifting 15.5-ounce cans from worktop to pantry using both hands), and playing video games (an Xbox One rally game). Participants performed each activity for 10 minutes with 30 -second transitions. The starting and finishing time of each activity were recorded with a stopwatch. The stopwatch and the internal clock of the accelerometer were synchronized to the same reference time. As a comparison, each participant wore an ActiGraph GT3X+ accelerometer during the experiment.

\section{Instrumentation}

\section{K-Sense wireless sensor system hardware}

The participants were fitted with the K-Sense wireless sensor system for light-intensity activities; the system consisted of two body-mounted sensors on the subjects' wrist and ankle. Technical specifications of the prototype device and early validation studies on the activity identification and EE have been reported previously [32, 33]. The K-Sense system utilizes SparkFun 9DoF Razor IMUs, involving 3-axis accelerometers (ADXL345), gyroscopes (IDG3200), and magnetometers (HMC5883L). Data are generated by the hardware's IMU and sent through a Bluetooth serial interface to a computer, where they are time-stamped and logged. The K-Sense uses an 800-mAh battery, but the prototype version does not utilize the on-board memory. The Bluetooth 4 wireless connectivity allows for $30 \mathrm{~m}$ of connectivity range to a laptop or cellphone, and the device continuously streams data to the base station for logging purposes. The size of each device is $1 \times 1$ inches, and a potential commercialized version of the K-Sense device is estimated to cost around \$150. The software platform for K-Sense is currently available and it is free for users.

\section{K-Sense energy estimation}

K-Sense is based on utilizing angular sensor data, provided by the IMU, to estimate the amount of work necessary to accomplish specific movements. For sim-

Table 1. Characteristics of the study participants

\begin{tabular}{lccc} 
& Females $(n=9)$ & Males $(n=9)$ & Total $(n=18)$ \\
\hline Age & $26.2(7.5)$ & $21.90(1.29)$ & $23.95(5.15)$ \\
Ethnicity/race $(\% \mathrm{w} / \mathrm{b})$ & $78 / 22$ & $100 / 0$ & $89 / 11$ \\
Height $(\mathrm{cm})$ & $162.0(7.9)$ & $183.3(4.9)$ & $172.7(12.4)$ \\
Weight $(\mathrm{kg})$ & $52.1(6.3)$ & $93.4(8.8)$ & $79.2(18.7)$ \\
BMI $\left(\mathrm{kg} / \mathrm{m}^{2}\right)$ & $26.5(2.1)$ & $28.6(4.0)$ & $27.1(5.3)$ \\
\hline
\end{tabular}

Values are means $(S D)$.

BMI was calculated with Centers for Disease Control software.

$\mathrm{w}$ - white, $\mathrm{b}$ - black, BMI - body mass index 
plicity, sensors were placed on the right side of the body on the wrist and ankle. It was assumed that each limb would be expending equal amounts of energy whether the arms are moving as a mirror image to each other or the arms and legs are moving in a counteracting manner. The K-Sense system utilizes 4-dimensional quaternion (a representation of a scalar sum and a 3-dimensional vector to represent the orientation of an object in a 3-dimensional space) vector-derived equations. Ultimately, total EE is a function of the angular movement of the arms and legs along with the basal metabolic rate for the core of the body, the amount of energy expended to maintain the body's core functions, typically based on a person's height, weight, and age $[36,37]$. K-Sense estimates EE where rotational work, $W=\tau \Theta$, is a function of, rotational force and $\Theta$, angular displacement. By combining momentum, I, and angular acceleration, $\alpha$, work becomes $\mathrm{W}=\mathrm{I} \alpha \Theta$. Angular acceleration is a function of tangential acceleration, $\alpha$ and the radius, $r$, from the limb joint to the limb centre of mass, resulting in work being defined as $\mathrm{W}=\mathrm{I}(\alpha / \mathrm{r})$. Finally, by combining angular velocity, $\omega$, with equations ac $=\omega^{2} r$ and $I=m r^{2}$, we derive:

$$
\mathrm{W}=m r^{2} \omega^{2} \Theta
$$

where $\mathrm{W}$, work, is a function of mass, $\mathrm{m}$, the radius squared, the angular velocity squared, and the angular displacement.

This equation forms the basis of the K-Sense energy estimator.

\section{Metabolic measurements}

Oxygen uptake and related variables were measured with the Parvo Medics’ TrueOne ${ }^{\circledR} 2400$ metabolic measurement system. The unit was turned on at least 30 minutes before each session, and the system was calibrated before every measurement in accordance with the manufacturer's instructions. This involved the pneumotachometer being calibrated with the use of five strokes of a 3-1 syringe at graduated flow-rates from $50-801 \cdot \mathrm{min}^{-1}$ up to $>400 \mathrm{l} \cdot \mathrm{min}^{-1}$. The gas analysers were calibrated with a 2-point fully automated process involving room air and a certified gas (3.98\% $\mathrm{CO}_{2}, 16.03 \% \mathrm{O}_{2}$, balance $\mathrm{N}_{2}$; Airgas Specialty Gases, Lenexa, U.S.). Fractions of oxygen and carbon dioxide were measured via a paramagnetic oxygen analyser and an infrared, single beam, single wave-length carbon dioxide analyser, respectively. During all experiments, the participants wore an 'over-the-nose' adapted mask that was connected by plastic tubing to the gas analyser.
Data were collected, stored, and reported on a breathby-breath basis, and EE was determined from the oxygen consumption and carbon dioxide production, and the volume of expired air, in accordance with the manufacturer's equations. The average measured oxygen consumption $\left(\mathrm{VO}_{2}\right)$ was determined and converted to relative $\mathrm{VO}_{2}\left(\mathrm{ml} \cdot \mathrm{kg}^{-1} \cdot \mathrm{min}^{-1}\right)$.

\section{Accelerometry}

The GT3X+ activity monitors (ActiGraph LLC, Pensacola, U.S.) were used. The GT3X+ is a 3-axial accelerometer designed to detect vertical accelerations (sensitive to movement along three axes) ranging in the magnitude of $\pm 6 g$ [38]. Thirty-Hz frequency responses with 1-second epoch were used. The devices were positioned on the participants' right midaxillary line at the level of the iliac crest, with elastic bands. Wrist- and waist-worn ActiGraph accelerometers have shown to be valid and reliable [39, 40]. The accelerometers were calibrated at the beginning and end of the study and each time were found to be within $\pm 3.5 \%$ of the reference value, which is within the manufacturer's standards. For each activity, accelerometer data were converted to average counts $\cdot \mathrm{min}^{-1}$ and entered appropriately into each equation to predict EE. EE estimates and validation protocols are presented in subsequent publications [20, 24, 29, 30]. The equation algorithms are presented in Table 2.

\section{Data analyses}

The accuracy of the K-Sense EE estimation technique was estimated and reported with the use of a mean standard error $(S E)$, that is a total error at the end of each trial, and root mean squared error (RMSE), a summation of each window's error across a trial. Indirect calorimetry-measured EE and K-Sense estimated EE were compared with 2-way mixed effects, absolute agreement, single-measurement, intra-class correlation coefficient (ICC) and paired-samples $t$-tests, with the statistical significance levels of 0.05 and 0.001. The Bland-Altman method was used to calculate the mean difference between the two methods of measurement, and $95 \%$ limits of agreement were applied for describing the total error between the two methods. Finally, paired-samples $t$-test analyses were conducted to determine whether ActiGraph-based EE estimations statistically significantly differed from the indirect calorimetry results. 


\section{HUMAN MOVEMENT}

S. Yli-Piipari, K.I. Zaman, J.C. Fish, T.W. Hnat, K-Sense energy expenditure assessment

\section{Ethical approval}

The research related to human use has been complied with all the relevant national regulations and institutional policies, has followed the tenets of the Declaration of Helsinki, and has been approved by the Institutional Review Board of the University of Memphis.

\section{Informed consent}

Informed consent has been obtained from all individuals included in this study.

\section{Results}

EE estimation accuracy of the K-Sense

Table 2 presents means and SEs showing that the K-Sense system was able to achieve EE accuracy ranging from $89.4 \%$ to $99.9 \%$. Best accuracy was obtained with the wrist and ankle solution from activities such as lying (99.9\%), sitting (98.3\%), and reading a book (97.3\%). Most inaccurate estimations were derived from monitor work (89.4\%) and putting away

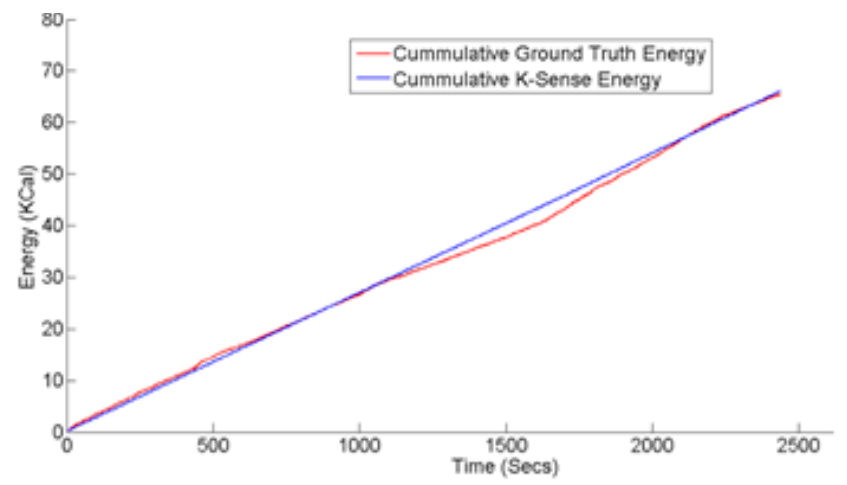

Figure 1. Energy expenditure is cumulative over time and in this example, K-Sense estimation tracks indirect calorimetry data. At the worst point, K-Sense is off by $4 \mathrm{kcal}$ before converging to $0.9 \mathrm{kcal}$

groceries (90.2\%). To understand the effects of the kinematic solution of the K-Sense, Figure 1 demonstrates the cumulative energy over time for a single trial, illustrating that the K-Sense estimates never exceed $4 \mathrm{kcal}$ away from the indirect calorimetry. Table 2 presents the measured EE for each activity, showing that K-Sense overestimated five activities (lying, sitting, standing,

Table 2. Accuracy of the K-Sense energy expenditure estimation and comparison of the estimation accuracy of the different energy estimation algorithms $(n=18)$

\begin{tabular}{|c|c|c|c|c|c|c|c|c|c|c|c|c|}
\hline \multirow[t]{2}{*}{ Activity } & \multirow[t]{2}{*}{$\begin{array}{l}\text { Activity } \\
\text { code }\end{array}$} & \multirow{2}{*}{$\begin{array}{c}\begin{array}{c}\text { Indirect } \\
\text { calorimetry }\end{array} \\
\text { kcal }\end{array}$} & \multicolumn{2}{|c|}{$\begin{array}{c}\text { K-Sense } \\
\text { (wrist and ankle) }\end{array}$} & \multicolumn{2}{|c|}{$\begin{array}{l}\text { Crouter } 2006[24] \\
2.330519+(0.00164 \\
\left.\times \text { counts } \cdot \mathrm{min}^{-1}\right)- \\
{[1.2017 \times 10-7 \times} \\
\left.\left(\text { counts } \cdot \mathrm{min}^{-1}\right) 2\right]+ \\
{[3.3779 \times 10-12 \times} \\
\left.\left(\text { counts } \cdot \mathrm{min}^{-1}\right) 3\right]\end{array}$} & \multicolumn{2}{|c|}{$\begin{array}{l}\text { Hendelman } 2000[20] \\
2.922+(0.000409 \times \\
\left.\quad \text { counts } \cdot \min ^{-1}\right)\end{array}$} & \multicolumn{2}{|c|}{$\begin{array}{c}\text { Schwarz } 2000[30] \\
2.606+ \\
(0.0006863 \times \\
\left.\text { counts } \cdot \min ^{-1}\right)\end{array}$} & \multicolumn{2}{|c|}{$\begin{array}{c}\text { Freedson VM3 Adult } \\
2011[29] \\
\text { VM3 Adult } \mathrm{kcal}^{\mathrm{a}} \cdot \mathrm{min}^{-} \\
=0.001064 \times \mathrm{VM}+ \\
0.087512(\mathrm{BM})- \\
5.500229\end{array}$} \\
\hline & & & kcal & $S E$ & kcal & $S E$ & kcal & $S E$ & kcal & $S E$ & kcal & $S E$ \\
\hline \multicolumn{13}{|l|}{ Session 1} \\
\hline Lying & 7010 & 11.54 & 11.53 & $0.148^{*}$ & 15.78 & 45.40 & 14.08 & 30.35 & 14.77 & 35.20 & 0.74 & 93.85 \\
\hline Sitting & 720 & 12.15 & 12.36 & $1.741^{*}$ & 15.27 & 33.89 & 13.84 & 22.32 & 14.39 & 25.88 & 0.46 & 96.38 \\
\hline Standing & 7040 & 12.21 & 12.59 & $3.061^{*}$ & 14.21 & 27.62 & 13.58 & 26.24 & 13.85 & 27.71 & 0.25 & 98.14 \\
\hline $\begin{array}{l}\text { Sweeping } \\
\text { floor }\end{array}$ & 5010 & 14.52 & 13.48 & $7.175^{*}$ & 14.79 & 32.14 & 14.22 & 27.34 & 15.04 & 29.95 & 0.37 & 97.35 \\
\hline \multicolumn{13}{|l|}{ Session 2} \\
\hline $\begin{array}{l}\text { Monitor } \\
\text { work }\end{array}$ & 9040 & 12.81 & 11.45 & $10.630^{*}$ & 14.24 & 34.31 & 13.57 & 30.89 & 14.16 & 70.85 & 0.24 & 98.16 \\
\hline $\begin{array}{l}\text { Reclining } \\
\text { and reading } \\
\text { a book }\end{array}$ & 9030 & 11.93 & 12.26 & $2.714^{*}$ & 14.16 & 31.23 & 13.60 & 26.86 & 13.74 & 29.28 & 0.12 & 98.96 \\
\hline $\begin{array}{l}\text { Putting away } \\
\text { groceries }\end{array}$ & 5055 & 14.50 & 13.08 & $9.802^{*}$ & 13.98 & 21.90 & 13.62 & 21.50 & 13.82 & 19.74 & 0.18 & 98.96 \\
\hline $\begin{array}{l}\text { Playing } \\
\text { video games }\end{array}$ & 9045 & 11.57 & 12.07 & $4.338^{*}$ & 14.98 & 39.68 & 13.87 & 31.91 & 14.21 & 33.08 & 0.48 & 96.32 \\
\hline
\end{tabular}

Activity code refers to the Physical Activity Compendium Activity Codes by Ainsworth et al. [35].

Sample size for session 2 activities was 16 .

a The unit of the Freedson equation is kcal, whereas the other equations units are in metabolic equivalents.

* K-Sense-derived SEs.

VM - vector magnitude, BM - body mass (kg), $S E$ - standard error 
Table 3. Component evaluation of the K-Sense

\begin{tabular}{lccccccc}
\hline \multirow{2}{*}{ Activity } & \multicolumn{2}{c}{$\begin{array}{c}\text { Indirect } \\
\text { calorimetry }\end{array}$} & \multicolumn{2}{c}{$\begin{array}{c}\text { K-Sense } \\
\text { (wrist and ankle) }\end{array}$} & \multicolumn{2}{c}{$\begin{array}{c}\text { K-Sense } \\
\text { (ankle) }\end{array}$} & \multicolumn{2}{c}{$\begin{array}{c}\text { K-Sense } \\
\text { (wrist) }\end{array}$} \\
\cline { 2 - 9 } & kcal & kcal & Error & kcal & Error & kcal & Error \\
\hline Session 1 & & & & & & & \\
Lying & 11.54 & 11.53 & 0.15 & 12.36 & 15.71 & 11.33 & 14.42 \\
Sitting & 12.15 & 12.36 & 1.74 & 13.25 & 16.48 & 12.15 & 13.31 \\
Standing & 12.21 & 12.59 & 3.06 & 13.54 & 21.08 & 12.36 & 18.39 \\
Sweeping floor & 14.52 & 13.48 & 7.18 & 14.48 & 60.30 & 13.29 & 25.48 \\
\hline Session 2 & & & & & & & \\
Monitor work & 12.81 & 11.45 & 10.63 & 12.28 & 25.96 & 11.25 & 26.68 \\
Reclining and reading a book & 11.93 & 12.26 & 2.714 & 13.18 & 23.28 & 12.04 & 18.41 \\
Putting away groceries & 14.50 & 13.08 & 9.80 & 17.85 & 46.31 & 12.01 & 20.82 \\
Playing video games & 11.57 & 12.06 & 4.34 & 12.96 & 28.84 & 11.86 & 24.36 \\
\hline
\end{tabular}

Table 4. Two-way random-effect, absolute agreement, single measurement ICC model with 95\% CIs compared against indirect calorimetry

\begin{tabular}{|c|c|c|c|c|c|c|c|c|c|c|}
\hline \multirow[b]{2}{*}{ Activity } & \multicolumn{2}{|r|}{ K-Sense } & \multicolumn{2}{|c|}{ Crouter 2006 [24] } & \multicolumn{2}{|c|}{ Hendelman 2000 [20] } & \multicolumn{2}{|c|}{ Schwarz 2000 [30] } & \multicolumn{2}{|c|}{$\begin{array}{c}\text { Freedson VM3 Adult } \\
2011 \text { [29] }\end{array}$} \\
\hline & ICC & $95 \% \mathrm{CI}$ & ICC & $95 \% \mathrm{CI}$ & ICC & $95 \% \mathrm{CI}$ & ICC & $95 \% \mathrm{CI}$ & ICC & $95 \% \mathrm{CI}$ \\
\hline \multicolumn{11}{|l|}{ Session 1} \\
\hline Lying & $0.922^{* *}$ & {$[0.790,0.971]$} & $0.457^{*}$ & {$[-0.231,0.786]$} & $0.700^{*}$ & {$[0.018,0.898]$} & $0.640^{*}$ & {$[-0.145,0.879]$} & 0.041 & {$[-0.065,0.244]$} \\
\hline Sitting & $0.909 * *$ & {$[0.703,0.964]$} & 0.466 & {$[-0.203,0.785]$} & $0.763^{*}$ & {$[0.264,0.903]$} & $0.712^{*}$ & {$[0.099,0.900]$} & 0.017 & {$[-0.046,0.153]$} \\
\hline Standing & $0.864^{* *}$ & {$[0.637,0.949]$} & $0.853 * *$ & {$[0.607,0.945]$} & $0.781^{*}$ & {$[0.415,0.918]$} & $0.781^{*}$ & {$[0.414,0.918]$} & 0.152 & {$[-1.267,0.683]$} \\
\hline Sweeping floor & $0.689^{*}$ & {$[0.168,0.884]$} & 0.487 & {$[-0.373,0.808]$} & $0.685^{*}$ & {$[0.086,0.872]$} & $0.597^{*}$ & {$[-0.076,0.849]$} & 0.040 & {$[-1.566,0.641]$} \\
\hline \multicolumn{11}{|l|}{ Session 2} \\
\hline Monitor work & $0.807^{* *}$ & {$[0.448,0.933]$} & $0.699 *$ & {$[0.140,0.895]$} & $0.726^{*}$ & {$[0.216,0.904]$} & $0.672^{*}$ & {$[0.062,0.886]$} & 0.058 & {$[-1.697,0.671]$} \\
\hline $\begin{array}{l}\text { Reclining and } \\
\text { reading a book }\end{array}$ & $0.901^{* *}$ & {$[0.695,0.959]$} & $0.707^{*}$ & {$[0.162,0.898]$} & $0.782^{*}$ & {$[0.376,0.924]$} & $0.702^{*}$ & {$[0.146,0.896]$} & 0.006 & {$[-0.780,0.648]$} \\
\hline $\begin{array}{l}\text { Putting away } \\
\text { groceries }\end{array}$ & $0.689^{*}$ & {$[0.111,0.891]$} & $0.597^{*}$ & {$[-1.153,0.859]$} & $0.677^{*}$ & {$[0.076,0.887]$} & $0.677^{*}$ & {$[0.076,0.887]$} & 0.149 & {$[-1.437,0.703]$} \\
\hline Playing video games & $0.739 *$ & {$[0.252,0.909]$} & $0.730^{*}$ & {$[0.226,0.906]$} & $0.605^{*}$ & {$[-0.130,0.862]$} & $0.704 *$ & {$[0.154,0.897]$} & 0.299 & {$[-1.006,0.755]$} \\
\hline
\end{tabular}

** F-test $p$-value $<0.001,{ }^{*}$ F-test $p$-value $<0.05$

ICC - intra-class correlation coefficient, CI - confidence interval, VM - vector magnitude

reading a book, and playing video games) and underestimated three activities (sweeping floors, monitor work, and putting away groceries), but none of these differences was statistically significant. Table 2 illustrates the differences between measured EE per activities against EE estimates on K-Sense, and Table 3 shows the accuracy between different K-Sense device combinations (wrist only, ankle only, wrist-ankle). Whereas a two-sensor (wrist-ankle) combination demonstrated an $89.4 \%$ to $99.9 \%$ EE estimation accuracy, one-sensor systems (wrist only, ankle only) achieved $87.6 \%$ accuracy at best.

As presented in Table 4, ICC tests between indirect calorimetry and K-Sense indicated excellent reliability in lying (ICC $=0.922 ; 95 \%$ confidence interval [CI]: [0.790, 0.971]), sitting (ICC $=0.909$; 95\% CI:
$[0.703,0.964])$, and book reading $(\mathrm{ICC}=0.901 ; 95 \% \mathrm{CI}$ : $[0.695,0.959])$. Although sweeping the floor, putting away groceries, and playing video games showed only moderate reliability ICCs, ranging between 0.689 and 0.739 , the ICC values were statistically significant at the 0.05 level. $T$-tests showed no statistically significant differences between measured and estimated EE ( $p$ values ranging from 0.121 to 0.974 ) (Table 5). BlandAltman plots reflect the difference between K-Sense measured EE and indirect calorimetry (Figure 2). The plots illustrate the problem with both underestimating and overestimating EE among individuals. The width of the $95 \%$ confidence limits of agreement varied from -9 to $7 \mathrm{kcal}$, indicating some discrepancies between the two methods for individual participants. 
S. Yli-Piipari, K.I. Zaman, J.C. Fish, T.W. Hnat, K-Sense energy expenditure assessment

Table 5. Paired samples $t$-test comparisons of the estimation accuracy of the different energy estimation algorithms

\begin{tabular}{|c|c|c|c|c|c|c|c|c|c|c|}
\hline \multirow{2}{*}{ Activity } & \multicolumn{2}{|c|}{ K-Sense } & \multicolumn{2}{|c|}{$\begin{array}{c}\text { Crouter } 2006 \\
{[24]}\end{array}$} & \multicolumn{2}{|c|}{$\begin{array}{l}\text { Hendelman } 2000 \\
{[20]}\end{array}$} & \multicolumn{2}{|c|}{$\begin{array}{c}\text { Schwarz } 2000 \\
{[30]}\end{array}$} & \multicolumn{2}{|c|}{$\begin{array}{l}\text { Freedson VM3 } \\
\text { Adult } 2011 \text { [29] }\end{array}$} \\
\hline & $t$ & $p$ & $t$ & $p$ & $t$ & $p$ & $t$ & $p$ & $t$ & $p$ \\
\hline \multicolumn{11}{|l|}{ Session 1} \\
\hline Lying & 0.03 & 0.974 & 4.20 & 0.001 & 3.75 & 0.002 & 4.42 & $<0.001$ & 12.69 & $<0.001$ \\
\hline Sitting & 0.41 & 0.687 & 2.82 & 0.012 & 2.58 & 0.019 & 3.39 & 0.003 & 14.69 & $<0.001$ \\
\hline Standing & 0.54 & 0.599 & 2.65 & 0.017 & 1.72 & 0.104 & 2.01 & 0.061 & 11.13 & $<0.001$ \\
\hline Sweeping floor & 1.10 & 0.288 & 0.20 & 0.844 & 0.29 & 0.773 & 0.34 & 0.711 & 12.47 & $<0.001$ \\
\hline \multicolumn{11}{|l|}{ Session 2} \\
\hline Monitor work & 1.64 & 0.121 & 1.37 & 0.190 & 0.80 & 0.435 & 1.26 & 0.228 & 10.42 & $<0.001$ \\
\hline Reclining and reading a book & 0.50 & 0.624 & 2.38 & 0.031 & 2.16 & 0.065 & 1.99 & 0.065 & 11.44 & $<0.001$ \\
\hline Putting away groceries & 1.34 & 0.200 & 0.56 & 0.586 & 0.95 & 0.358 & 0.74 & 0.472 & 13.56 & $<0.001$ \\
\hline Playing video games & 0.60 & 0.556 & 4.52 & $<0.001$ & 3.06 & 0.008 & 3.27 & 0.005 & 13.88 & $<0.001$ \\
\hline
\end{tabular}

VM - vector magnitude
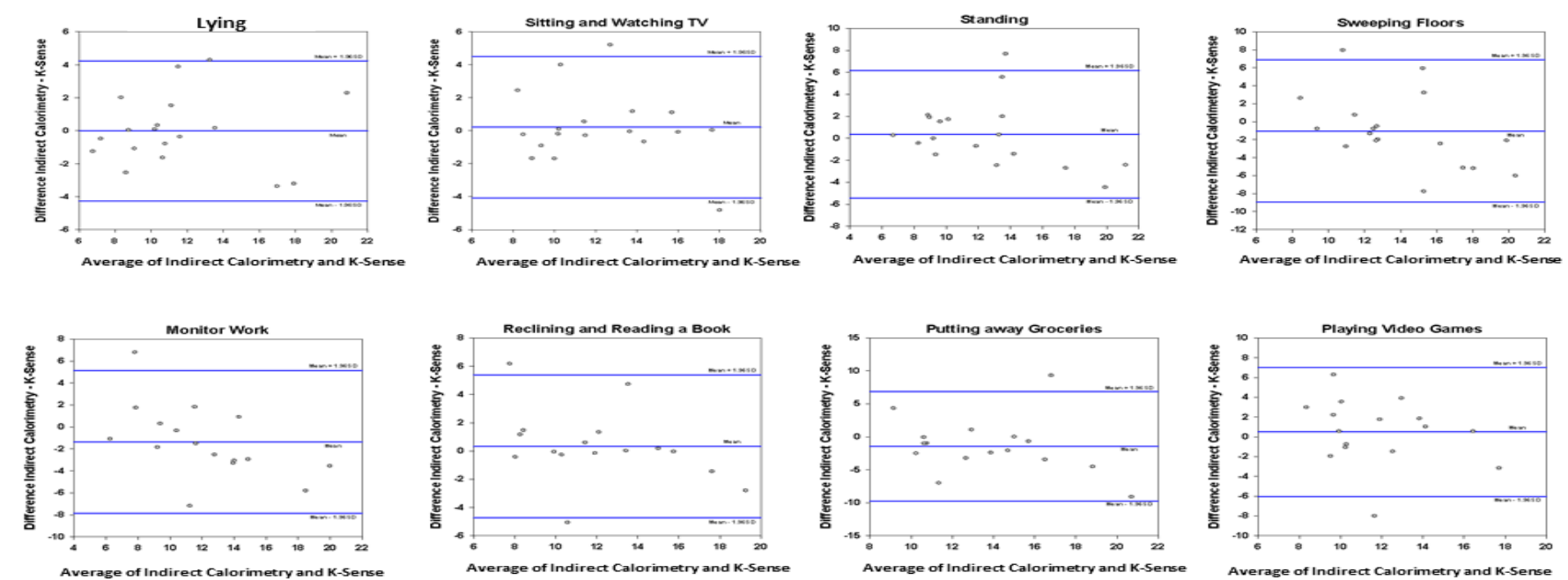

Figure 2. Bland-Altman comparison of the indirect calorimetry and K-Sense EE estimation models. Y-axis presents the difference between indirect calorimetry and K-Sense estimations, and X-axis displays the averages

\section{Comparison of the EE estimates}

The differences between indirect calorimetry-derived, K-Sense predicted and waist-mounted ActiGraph accelerometer-derived EE values are presented in Table 2. ActiGraph algorithms overestimated EE of light-intensity activities, achieving a $70.3 \%$ estimation accuracy at best. Table 4 presents the paired $t$-test values for between indirect calorimetry, KSense, and ActiGraph EE values. The findings of the paired $t$-tests showed that the Crouter [24], Hendelman [20], and Schwarz [30] algorithms did not statistically differ from indirect calorimetry values in three activities (sweeping floors, monitor work, and putting away groceries). In addition, the Hendelman [20] and Schwarz [30] algorithms provided similar EE estimates in the standing and reading a book activities.

\section{Discussion}

The presented laboratory study involved eight simulated sedentary to light-intensity tasks, showing an improved accuracy compared with the previous efforts to validate the K-Sense monitoring system [34, 35]. Similarly, when compared with the ActiGraph (GT3X+) accelerometer-derived EE estimates, this study reported higher estimation accuracy than the existing regression-based algorithms [20, 24, 29, 30].

The study proved that the K-Sense monitoring system was able to achieve reasonable EE accuracy when compared with indirect calorimetry, ranging from $89.4 \%$ to $99.9 \%$, with the error never exceeding $4 \mathrm{kcal}$. The paired $t$-test analyses showed that the K-Sense EE estimation values did not statistically significantly differ from the EE values measured by indirect calo- 
rimetry. The study demonstrates that unobtrusive and open source PA monitoring can improve the accuracy of EE of light-intensity movements. Best estimation accuracy was achieved in activities such as lying (99.9\%), sitting (98.3\%), and book reading (97.3\%).

Increased estimation accuracy can contribute to population health by improving the accuracy of everyday EE among the overweight and elderly, which are the subgroups that have shown to overestimate their habitual PA EE $[5,9,10]$. The findings of this study showed an improved EE estimation accuracy in comparison with the previously reported $92 \%$ estimation accuracy [32, 33].

This improvement was mostly due to increased monitoring time ( 4 minutes of data in the study by Zaman et al. [32] and 10 minutes of data in this study). Increased number of measurement points, i.e., repeated measurements, will reduce the signal/noise ratio, and thus increase accuracy.

The less accurate estimations were derived from monitor work (89.4\%) and putting away groceries $(90.2 \%)$. A partial explanation for these estimates is our assumption of limb symmetry, i.e., the assumption that limb movements would counteract each other, expending equal amounts of energy. In addition, the source of error could be improved by weighing body parts and basal metabolic rate more carefully. The largest impact of the basal metabolic rate-related measurement error is expected to be in the EE estimation of low-intensity activities. The lower the intensity level of activities, the greater the proportional value of $\mathrm{EE}$ is due to basal metabolic rate.

When comparing with ActiGraph accelerometerderived EE estimates, the K-Sense approach was able to achieve improved accuracy. The study reported that the assessed regression algorithms overestimated EE of the light-intensity activities, achieving only $70.3 \%$ estimation accuracy at best. Whereas $t$-test analyses did not show any statistically significant difference between K-Sense and indirect calorimetry EE values in any activities, the analyses proved that the Hendelman [20] and Schwarz [30] accelerometer equations were able to achieve statistically significant estimation accuracy in five out of eight activities. Previous studies have shown regression-based EE equations to overestimate the actual EE of light-intensity activities [23, 24]. However, recently, ActiGraph accelerometers have been found to underestimate the EE (26\%) of the free-living activities measured by whole room indirect calorimetry [41].

It is important to design and improve current technology to enhance the accuracy of accelerometer-based
EE estimation and to facilitate successful weight management [8]. Currently available technology, including K-Sense, can provide researches with relatively accurate EE estimates. In the future, we envision a kinematic solution that can be integrated into common wearable platforms such as a smartphone, shoes, and watches.

There were some limitations that need to be addressed when interpreting the results. First, this examination was conducted with the K-Sense prototype, which is not ready for commercialization. Therefore, the cost estimations are dependent on the hardware prices. It is notable that the software is currently freely available. Second, it should be emphasized that the steady state for each activity was not established for entire 10 minutes but an average 8 minutes 42 seconds $(S D=4.32 \mathrm{~s})$ per activity. Thus, the EE estimates of the eight activities should not be interpreted as accurate descriptions of the $\mathrm{EE}$ of each of these activities, but laboratory simulations of eight light-intensity activities. In addition, the participants' basal metabolic rate was estimated on the basis of their height, weight, and age [36, 37], and not measured objectively in laboratory. Although this contributes to the measurement error, this approach is widely applied because it is costand time-effective and provides good accuracy [32, 33]. The usage of the dual-energy X-ray absorptiometry for basal metabolic rate indication can increase the accuracy of the estimation [33]. However, the cost of this increased accuracy comes with the financial burden. Moreover, our sample consisted of lean and obese participants. It may be that the error in the K-Sense EE estimation was partly due to this variability in our sample. Finally, this manuscript compared the K-Sense algorithm with the linear regression-based algorithms. Lately, neural networks or pattern-recognition techniques have shown improved accuracy compared with the linear regression approaches [16].

\section{Conclusions}

This study showed that the K-Sense monitoring system was able to achieve a reasonable EE accuracy, with the error never exceeding $4 \mathrm{kcal}$, and the error did not differ from that of indirect calorimetry. In addition, the K-Sense equations allowed to achieve a higher accuracy across all measured activities compared with the accelerometer-based EE estimations.

\section{Acknowledgements}

The authors want to acknowledge the help of Lisa Smith in collecting the data. 
S. Yli-Piipari, K.I. Zaman, J.C. Fish, T.W. Hnat, K-Sense energy expenditure assessment

\section{Disclosure statement}

No author has any financial interest or received any financial benefit from this research.

\section{Conflict of interest}

The authors state no conflict of interest.

\section{References}

1. Ogden CL, Carroll MD, Kit BK, Flegal KM. Prevalence of childhood and adult obesity in the United States, 2011-2012. JAMA. 2014;311(8):806-814; doi: 10.1001/ jama.2014.732.

2. Finkelstein EA, Trogdon JG, Cohen JW, Dietz W. Annual medical spending attributable to obesity: payer-and service-specific estimates. Health Aff. 2009;28(5): w822-w831; doi: 10.1377/hlthaff.28.5.w822.

3. Westerterp KR. Energy metabolism and body composition: general principles. ERS Monograph. 2003;24:1-10.

4. Corder K, Ekelund U, Steele RM, Wareham NJ, Brage S. Assessment of physical activity in youth. J Appl Physiol. 2008;105(3):977-987; doi: 10.1152/japplphysiol.00094. 2008.

5. Walsh MC, Hunter GR, Sirikul B, Gower BA. Comparison of self-reported with objectively assessed energy expenditure in black and white women before and after weight loss. Am J Clin Nutr. 2004;79(6):1013-1019; doi: 10.1093/ajcn/79.6.1013.

6. Willbond SM, Laviolette MA, Duval K, Doucet E. Normal weight men and women overestimate exercise energy expenditure. J Sports Med Phys Fitness. 2010;50(4): 377-384.

7. Duncan GE, Sydeman SJ, Perri MG, Limacher MC, Martin AD. Can sedentary adults accurately recall the intensity of their physical activity? Prev Med. 2001; 33(1):18-26; doi: 10.1006/pmed.2001.0847.

8. Troiano RP, Berrigan D, Dodd KW, Mâsse LC, Tilert T, McDowell M. Physical activity in the United States measured by accelerometer. Med Sci Sports Exerc. 2008; 40(1):181-188; doi: 10.1249/mss.0b013e31815a51b3.

9. Norman A, Bellocco R, Bergström A, Wolk A. Validity and reproducibility of self-reported total physical activity - differences by relative weight. Int J Obes Relat Metab Disord. 2001;25(5):682-688; doi: 10.1038/sj. ijo.0801597.

10. Buchowski MS, Townsend KM, Chen KY, Acra SA, Sun M. Energy expenditure determined by self-reported physical activity is related to body fatness. Obes Res. 1999;7(1):23-33; doi: 10.1002/j.1550-8528.1999.tb00 387.x.

11. Chen KY, Rothney MP, Brychta RJ. Physical activity monitors: do more sensors mean better precision? J Diabetes Sci Technol. 2007;1(5):768-770; doi: 10.1177/ 193229680700100523.

12. Butler PJ, Green JA, Boyd IL, Speakman JR. Measuring metabolic rate in the field: the pros and cons of the doubly labelled water and heart rate methods. Funct
Ecol. 2004;18(2):168-183; doi: 10.1111/j.0269-8463. 2004.00821.x.

13. Troiano RP, McClain JJ, Brychta RJ, Chen KY. Evolution of accelerometer methods for physical activity research. Br J Sports Med. 2014;48(13):1019-1023; doi: 10.1136/bjsports-2014-093546.

14. John D, Freedson P. ActiGraph and Actical physical activity monitors: a peek under the hood. Med Sci Sports Exerc. 2012;44(1 Suppl 1):S86-S89; doi: 10.1249/MSS. 0b013e3182399f5e.

15. Butte NF, Ekelund U, Westerterp KR. Assessing physical activity using wearable monitors: measures of physical activity. Med Sci Sports Exerc. 2012;44(1 Suppl 1): S5-S12; doi: 10.1249/MSS.0b013e3182399c0e.

16. Liu S, Gao RX, Freedson PS. Computational methods for estimating energy expenditure in human physical activities. Med Sci Sports Exerc. 2012;44(11):21382146; doi: 10.1249/MSS.0b013e31825e825a.

17. Plasqui G, Joosen AM, Kester AD, Goris AH, Westerterp KR. Measuring free-living energy expenditure and physical activity with triaxial accelerometry. Obes Res. 2005;13(8):1363-1369; doi: 10.1038/oby.2005.165.

18. Brage S, Wedderkopp N, Franks PW, Andersen LB, Froberg K. Reexamination of validity and reliability of the CSA monitor in walking and running. Med Sci Sports Exerc. 2003;35(8):1447-1454; doi: 10.1249/01.MSS. 0000079078.62035.EC.

19. Freedson PS, Melanson E, Sirard J. Calibration of the Computer Science and Applications, Inc. accelerometer. Med Sci Sports Exerc. 1998;30(5):777-781; doi: 10.1097/ 00005768-199805000-00021.

20. Hendelman D, Miller K, Baggett C, Debold E, Freedson $\mathrm{P}$. Validity of accelerometry for the assessment of moderate intensity physical activity in the field. Med Sci Sports Exerc. 2000;32(9 Suppl):S442-S449; doi: 10.1097/00005768-200009001-00002.

21. Leenders NY, Nelson TE, Sherman WM. Ability of different physical activity monitors to detect movement during treadmill walking. Int J Sports Med. 2003; 24(1):43-50; doi: 10.1055/s-2003-37196.

22. Nichols JF, Morgan CG, Chabot LE, Sallis JF, Calfas KJ. Assessment of physical activity with the Computer Science and Applications, Inc., accelerometer: laboratory versus field validation. Res Q Exerc Sport. 2000;71(1): 36-43; doi: 10.1080/02701367.2000.10608878.

23. Yngve A, Nilsson A, Sjostrom M, Ekelund U. Effect of monitor placement and of activity setting on the MTI accelerometer output. Med Sci Sports Exerc. 2003;35(2): 320-326; doi: 10.1249/01.MSS.0000048829.75758.A0.

24. Crouter SE, Clowers KG, Bassett DR Jr. A novel method for using accelerometer data to predict energy expenditure. J Appl Physiol. 2006;100(4):1324-1331; doi: 10.1152/japplphysiol.00818.2005.

25. Bassett DR Jr., Ainsworth BE, Swartz AM, Strath SJ, O’Brien WL, King GA. Validity of four motion sensors in measuring moderate intensity physical activity. Med Sci Sports Exerc. 2000;32(9 Suppl):S471-S480; doi: 10.1097/00005768-200009001-00006. 
26. Vathsangam H, Emken A, Spruijt-Metz D, Sukhatme G. Toward free-living walking speed estimation using Gaussian process-based regression with on-body accelerometers and gyroscopes. $4^{\text {th }}$ International Conference on Pervasive Computing Technologies for Healthcare, 22-25 March 2010; 6497-6501; doi: 10.4108/ICST. PERVASIVEHEALTH2010.8786.

27. Pober DM, Staudenmayer J, Raphael C, Freedson PS. Development of novel techniques to classify physical activity mode using accelerometers. Med Sci Sports Exerc. 2006;38(9):1626-1634; doi: 10.1249/01.mss.0000227542. 43669.45 .

28. Ellis K, Kerr J, Godbole S, Lanckriet G, Wing D, Marshall S. A random forest classifier for the prediction of energy expenditure and type of physical activity from wrist and hip accelerometers. Physiol Meas. 2014;35(11): 2191-2203; doi: 10.1088/0967-3334/35/11/2191.

29. Sasaki JE, John D, Freedson PS. Validation and comparison of ActiGraph activity monitors. J Sci Med Sport. 2011;14(5):411-416; doi: 10.1016/j.jsams.2011.04.003.

30. Swartz AM, Strath SJ, Bassett DR Jr., O’Brien WL, King GA, Ainsworth BE. Estimation of energy expenditure using CSA accelerometers at hip and wrist sites. Med Sci Sports Exerc. 2000;32(9 Suppl):S450-S456; doi: 10.1097/00005768-200009001-00003.

31. Young DR, Jerome GJ, Chen C, Laferriere D, Vollmer WM. Patterns of physical activity among overweight and obese adults. Prev Chronic Dis. 2009;6(3):A90.

32. Zaman KI, Yli-Piipari S, Hnat TW. Kinematic-based sedentary and light-intensity activity detection for wearable medical applications. $1^{\text {st }}$ Workshop on Mobile Medical Applications'14, November 6, 2014, Memphis, TN,USA.2014;28-33; doi:10.1145/2676431.2676433.

33. Zaman KI, White A, Yli-Piipari S, Hnat TW. K-Sense: towards a kinematic approach for measuring human energy expenditure. Wireless Sens Net. 2014;8354: 166-181; doi: 10.1007/978-3-319-04651-8_11.

34. Warburton DER, Jamnik VK, Bredin SSD, Gledhill N. The Physical Activity Readiness Questionnaire for Everyone (PAR-Q+) and Electronic Physical Activity Readiness Medical Examination (ePARmed-X+). Health Fitness J Canada. 2011;4(2):3-23.

35. Ainsworth BE, Haskell WL, Herrmann SD, Meckes N, Bassett DR Jr., Tudor-Locke C, et al. 2011 Compendium of Physical Activities: a second update of codes and MET values. Med Sci Sports Exerc. 2011;43(8):15751581; doi: 10.1249/MSS.0b013e31821ece12.

36. De Leva P. Adjustments to Zatsiorsky-Seluyanov's segment inertia parameters. J Biomech. 1996;29(9):12231230; doi: 10.1016/0021-9290(95)00178-6.

37. Plagenhoef S, Evans FG, Abdelnour T. Anatomical data for analyzing human motion. Res Q Exerc Sport. 1983; 54(2):169-178; doi:10.1080/02701367.1983.10605290.

38. ActiGraph. Actilife 6 web site. Available from: https:// www.actigraphcorp.com/support/software/actilife/.

39. Aadland E, Ylvisåker E. Reliability of objectively measured sedentary time and physical activity in adults.
PLoS One. 2015;10(7):e0133296; doi: 10.1371/journal.pone.0133296.

40. Aadland E, Ylvisåker E. Reliability of the Actigraph GT3X+ accelerometer in adults under free-living conditions. PLoS One. 2015;10(8):e0134606; doi: 10.1371/ journal.pone.0134606.

41. Dannecker KL, Sazonova NA, Melanson EL, Sazonov ES, Browning RC. A comparison of energy expenditure estimation of several physical activity monitors. Med Sci Sports Exerc. 2013;45(11):2105-2112; doi: 10.1249/ MSS.0b013e318299d2eb. 